\title{
Peer mentoring: A move towards addressing inequality between $\mathrm{PhD}$ students
}

\author{
Justine Fam ${ }^{1} 1, *$ and Jessica C. Lee ${ }^{1} 1$ \\ ${ }^{1}$ School of Psychology, UNSW Sydney, Sydney, New South Wales, Australia. \\ *j.fam@unsw.edu.au
}

\begin{abstract}
The number of students enrolling in postgraduate by research degrees has seen a large increase in recent years, a trend which is evident globally as well as within Australia. However, the rate at which PhD students are dropping out has also increased, indicating that students are not receiving adequate resources to support them throughout their candidature. We highlight that mentoring programs are effective in addressing inequality between $\mathrm{PhD}$ students, and describe a program that we have recently launched at UNSW Sydney.
\end{abstract}

Key words: Careers; Mental Health; PhD students; Mentoring

PhD students play a vital role in shaping the future of academic research. The $\mathrm{PhD}$ candidature involves years of intense work dedicated to a single topic, providing a strong research foundation that enables later significant breakthroughs to be made. In Australia, there has been a large increase in the number of students who commence postgraduate by research degrees, reflecting a broader global trend of increased $\mathrm{PhD}$ enrolments [1]. In this article, we focus on students in Psychology and Neuroscience. In the five-year period between 2003 and 2007, the number of student enrolments was 75,789 according to the Australian Government Department of Education and Training. Between 2013 and 2017, this number increased by $56.5 \%$ to 118,646 enrolments. However, there is a discrepancy between the increase in enrolments and the increase in completions, indicating that the rate at which students are dropping out of their postgraduate research degrees has exceeded the growth in enrolments. This attrition is particularly high for the rapidly growing population of international students, whose $\mathrm{PhD}$ enrolments have more than doubled from 20032007 to 2013-2017. Thus, the overall picture indicates a worrying trend of increased student attrition in Australia, for which international students are a particularly vulnerable cohort.

Current understanding of the discrepancy between the increase in enrolments and completions within Australia is poor, as most research on student success in higher education has focused on domestic students at the undergraduate level [2]. However, research from North America, Canada and the UK identify several factors that may lead to study drop-out, such as high workload, funding pressures and supervisory relationships [3-6]. Such research has also highlighted that two critical factors are isolation and poor social support, which might have particularly strong effects for students who are relocating either internationally or across state lines and have added pressures of having to cope with new physical and cultural environments [7]. Indeed, several studies have identified that support, both in terms of social support networks and mentorship, is a key determinant of academic success. For example, in a review of higher education research, Sverdlik, Hall, McAlpine, and Hubbard (2018) concluded that alongside supervision, institutional support and socialization were among the most important external factors predicting student success [8]. Although universities have the potential to provide opportunities for meaningful social interactions, it would be beneficial for students, particularly those that are most vulnerable to high attrition rates, to have access to structured programs that are dedicated to creating opportunities for social support and mentoring. Such mentoring programs for undergraduate and honours students and have been shown to be successful [9], but they are rarely organised for $\mathrm{PhD}$ students.

One reason for the pivotal role mentorship plays is that it provides much-needed guidelines for a largely unstructured academic program within a heterogeneous discipline. There is great variability in the experience of Australian Psychology PhD students; depending on the sub-discipline, a student may undertake research as part of a large research team and benefit from high levels of support and guidance, or work on a project that is a relatively individual pursuit. Students who are part of a conducive research team have greater opportunity and access to mentorship, which facilitates the development of skills necessary for success in academia. These skills in- 
clude the 'hard skills' such as experimental design, statistics, computer programming and other field-specific skills such as stereotaxic rodent surgery or computational modelling, as well as 'soft skills' such as confidence in public speaking, the ability to make sense of complex information and effective networking. Mentors also provide critical social and psychological support throughout the $\mathrm{PhD}$ candidature, which has been recognised as an emotionally challenging period during which students are at risk of developing clinically significant mental health issues [10-12]. Thus, some students have an advantage conferred to them by virtue of lab membership as distinct from intrinsic ability per se. This can lead to a sense of inequality and disengagement of equally talented students who do not have access to such support and view academia as an uneven playing field.

At UNSW Sydney, we recently started an opt-in mentoring program which aims to alleviate the inequality in access to social support and mentorship faced by $\mathrm{PhD}$ students via three key components. The first key feature is that it is designed to meet the needs of students. Before our mentoring program was launched, we asked $\mathrm{PhD}$ students to provide us with issues that they wanted the program to address, and designed the program according to the responses we received. The success of the program is also monitored regularly, to ensure that we continue to address the changing needs of students. We believe that our policy of being responsive to the needs of the students is vital for providing effective support and is one reason our program has been successful in attracting a large number of students.

The second key component of our program is that each $\mathrm{PhD}$ student is paired with a mentor who is an early career researcher within the School of Psychology. Student-mentor pairs are provided with guidelines for how to maximise their student-mentor relationship: we encourage monthly meetings and provide a handbook with suggested discussion topics (e.g., how to network, how to have difficult conversations). We also provide mentors with a range of training resources to develop their approach to mentoring (e.g. the GROW model). It is important for our mentoring program to consider the heterogeneous nature of a psychology $\mathrm{PhD}$ and student's experiences. Thus, we emphasise that the structure of the program is flexible and should be tailored to the individual needs of students. Students who are seeking to establish more social connections may prefer group meetings, while students who require emotional support on sensitive issues may desire the privacy of oneto-one meetings. Currently, many early career researchers have volunteered as mentors, giving our program a ratio of approximately two students to each mentor.

The third key feature of our program is targeted events, such as social networking and question-and-answer format information sessions that all students and mentors are encouraged to attend. The specific aim of each event is determined according to issues that students have indicated interest in. For example, the majority of our students expressed an interest in learning about careers outside of academia. Accordingly, we organised a session to provide students with more information. At this event, we invited a panel of speakers consisting of STEM PhD graduates who recently made the transition from academia to industry or government jobs. The event started with panel speakers responding to questions that students had about their work outside of academia, prompting a lively discussion between the panel and students. Students then had the opportunity to network with the panel members afterwards. Such events offer many benefits, two of which we wish to highlight: firstly, they foster a sense of community and belonging, which has been identified as a key factor in determining academic success [4]. Secondly, they provide students with valuable but elusive information; nearly $80 \%$ of $\mathrm{PhD}$ graduates end up in careers outside of academia, yet there is a dearth of knowledge about what alternative career options are available for STEM PhD graduates, and how to pursue them. It is worth noting that O'Meara et al. (2014) found that institutions that approved of academic and non-academic career paths, and facilitated networking within the department, empowered students' sense of agency in their careers [13]. Indeed, the feedback we received (from both students and mentors) about the event was overwhelmingly positive.

We feel that mentoring programs are a critical step towards addressing the high attrition rate of $\mathrm{PhD}$ students. Since $\mathrm{PhD}$ students will become future tenured academics, and therefore, shape the direction that Psychology research will take, it is important that we provide support to enable the best opportunity for talented students to remain in academia. Without active programs, universities risk suffering a talent drain. It would be a shame if students with academic potential were driven out due to poor social support, lack of guidance, or other factors unrelated to intellectual aptitude.

\section{Declarations}

\section{Acknowledgements}

The peer mentoring program is supported by the School of Psychology, UNSW Sydney.

\section{Conflict of Interest Declaration}

The authors declare no conflicts of interest.

\section{References}

1. OECD. Who are the doctorate holders and where do their qualifications lead them?. vol. 25 of Education Indicators in Focus. Paris: OECD Publishing; 2014. Available from: https://doi.org/10.1787/5jxv8xsvp1g2-en.

2. Ampaw FD, Jaeger AJ. Completing the three stages of doctoral education: An event history analysis. Research in Higher Education. 2012;53(6):640-660. doi:10.1007/s11162-011-9250-3.

3. Juniper B, Walsh E, Richardson A, Morley B. A new approach to evaluating the well-being of $\mathrm{PhD}$ research students. Assessment \& Evaluation in Higher Education. 2012;37(5):563-576. doi:10.1080/02602938.2011.555816.

4. Pearson M. Building bridges: Higher degree student retention and counselling support. Journal of Higher Education Policy and Management. 2012;34(2):187-199. doi:10.1080/1360080X.2012.662743.

5. Peluso DL, Carleton RN, Asmundson GJG. Depression symptoms in Canadian psychology graduate students: Do research productivity, funding, and the academic advisory relationship play a role? Canadian Journal of Behavioural Science. 2011;43(2):119-127. doi:10.1037/a0022624.

6. Waight E, Giordano A. Doctoral students' access to nonacademic support for mental health. Journal of Higher Education Policy and Management. 2018;40(4):390-412. doi:10.1080/1360080X.2018.1478613.

7. Soong H, Thi Tran L, Hoa Hiep P. Being and becoming an intercultural doctoral student: Reflective autobiographical narratives. Reflective Practice. 2015;16(4):435-448. doi:10.1080/14623943.2015.1023276.

8. Sverdlik A, Hall NC, McAlpine L, Hubbard K. Journeys of a $\mathrm{PhD}$ student and unaccompanied minors. International Journal of Doctoral Studies. 2018;13:361-388. doi:10.28945/4113. 
9. Khoo SYS, Zhao J, Walker A, Kirkman J, Spehar B. Transitions and choices: Graduate student mentoring for psychology honours students. A practice report. Student Success. 2019;10(1):147-154. doi:10.5204/ssj.v10i1.648.

10. Evans TM, Bira L, Gastelum JB, Weiss LT, Vanderford NL. Evidence for a mental health crisis in graduate education. Nature Biotechnology. 2018;36:282-284. doi:10.1038/nbt.4089.

11. Levecque K, Anseel F, De Beuckelaer A, Van der Heyden J, Gisle L. Work organization and mental health problems in $\mathrm{PhD}$ students. Research Policy. 2017;46(4):868-879. doi:10.1016/j.respol.2017.02.008.

12. Mantai L, Dowling R. Supporting the $\mathrm{PhD}$ journey: Insights from acknowledgements. International Journal for Researcher Development. 2015;6(2):106-121. doi:10.1108/IJRD-03-2015-0007.

13. O'Meara K, Jaeger A, Eliason J, Grantham A, Cowdery K, Mitchall A, et al. By design: How departments influence graduate student agency in career advancement. International Journal of Doctoral Studies. 2014;9:155-179. doi:10.28945/2048.

\section{Copyright and License}

Copyright (c) 2019. The Author(s). Except where otherwise noted, the content of this article is licensed unde a Creative Commons Attribution 4.0 International License. You are free to reuse or adapt this article for any purpose, provided appropriate acknowledgement is provided. For additional permissions, please contact the corresponding author. 